\title{
Manifestaciones oculares en la enfermedad por coronavirus SARS-CoV-2. ¿Qué sabemos?
}

\author{
Ocular manifestations in SARS-CoV-2 coronavirus disease. What do we know?
}

\section{Sr. Editor:}

La enfermedad por COVID-19 es producida por el virus SARS-CoV-2, que consta de un RNA monocatenario y cuatro tipos de proteínas: proteína de espiga (S), proteína de membrana (M), envoltura (E) y nucleocápside $(\mathrm{N})$, siendo la proteína $\mathrm{S}$ la responsable de la unión a los receptores de membrana del huésped (1). La proteína $\mathrm{S}$ se acopla a las células con los receptores de angiotensina 2 (ACE 2), las cuales se encuentran presentes en la superficie ocular (células del epitelio conjuntival y corneal), lo que explicaría un mecanismo alternativo de infección, aunque los detalles de este tropismo están aún en estudio (2). Se han realizado investigaciones donde se ha podido encontrar material genético del virus en secreción lagrimal de los pacientes enfermos de COVID-19, lo que justifica el uso de gafas protectoras en el personal de salud $(1,3)$.

Se considera que existen dos vías por las que el virus puede afectar a los ojos: primario y secundario. En el compromiso ocular primario el virus entra en contacto directo con la superficie ocular y el sistema inmunitario local ocasionando una conjuntivitis (lagrimeo, hiperemia conjuntival intensa, quemosis conjuntival, descarga acuosa), siendo esta la principal manifestación ocular reportada. Luego las secreciones pasan a través del conducto nasolagrimal hacia el tracto respiratorio superior pudiendo llegar el virus de esta manera a los pulmones, siendo esta vía preferentemente unidireccional porque existen válvulas en su recorrido que evitan el reflujo lagrimal $(2,4,5)$. En el compromiso ocular secundario, el virus viaja por vía hematógena, llegando así hasta la glándula lagrimal y a los tejidos intraoculares (retina, úvea, nervio óptico) a través de la arteria oftálmica y sus colaterales (arteria central de la retina, arterias ciliares posteriores) $(4,5,6,7)$.

La prevalencia de conjuntivitis en pacientes COVID-19 es de aproximadamente 5,5\%. Con respecto a los estudios donde se tomaron muestras de hisopado conjuntival, se llegó a detectar material genético viral entre $1 \%$ a $7 \%$ de los pacientes. Esta baja tasa de positividad del hisopado conjuntival se podría deber a una toma inadecuada de la muestra, la carga viral conjuntival, momento de la enfermedad en el que se tomó la muestra, respuesta del sistema inmunitario ocular local, drenaje constante de la lágrima y frecuencia del parpadeo $(6,7)$.

La conjuntivitis es la manifestación más frecuente del compromiso ocular por el SARS- CoV2. Se ha encontrado asociación entre la presencia de conjuntivitis y la severidad de la enfermedad por COVID-19 en pacientes hospitalizados (5). Además, se han reportado casos leves de retinitis en pacientes con COVID-19 a los que se les realizó un fondo de ojo y una tomografía de coherencia óptica con tecnología swept source, encontrándose micro hemorragias y lesiones algodonosas en la capa de células ganglionares y plexiforme interna a nivel del haz papilo-macular. (8). También se han reportado algunos casos de epiescleritis, queratoconjuntivitis, uveítis anterior y parálisis del VI par en pacientes con COVID-19 $(1,2,6)$.

\footnotetext{
1. Servicio de Oftalmología, Hospital Nacional Hipólito Unanue. Lima. Perú.

2. Facultad de Medicina Humana, Unidad de Posgrado, Universidad San Martín de Porres. Lima. Perú.

3. Facultad de Medicina Humana, Universidad Nacional Federico Villarreal. Lima. Perú.

a. Médico Cirujano Oftalmólogo.

b. Médico Residente de Oftalmología.
} 
El antecedente de ser un virus zoonótico y que haya presentado mutaciones previas, hace que estemos atentos a la aparición de nuevas formas clínicas de afectación ocular, que de encontrarse en los pacientes deben ser reportados de inmediato al oftalmólogo porque podrían conducir a la ceguera irreversible (4). En este sentido se debe siempre preguntar a los pacientes sobre su estado visual y enseñarle los signos de alarma oculares (dolor, ojo rojo, disminución súbita de visión, y aparición de secreciones oculares).

Se requiere mayor cantidad de investigaciones para construir una evidencia sólida y determinar las características epidemiológicas, clínicas, factores de riesgo y complicaciones del compromiso ocular en los pacientes con enfermedad por COVID-19.

\section{Fernando Munayco-Guillén 1,2, a, Sarita Milagros Fernández-Poma ${ }^{1,3, b}$, Ileng Ingrid Nakagawa Yep ${ }^{1,3, b}$, Cesar Joaquín Aguirre-Rocca ${ }^{1,3, b}$.}

\section{Correspondencia:}

Fernando Munayco Guillén.

Dirección: Av. Antonio José de Sucre 430. Departamento 306. Pueblo Libre. Lima. Perú.

Correo: fernando.munayco.guillen@gmail.com

\section{REFERENCIAS BIBLIOGRÁFICAS}

1. Bostanci-Ceran B, Ozates S. Ocular manifestations of coronavirus disease 2019. Graefes Arch Clin Exp Ophthalmol. 2020; 1-5. doi:10.1007/s00417-02004777-7
2. Ho D, Low R, Louis Tong, Gupta V, Veeraraghavan A, Agrawal R. COVID-19 and the Ocular Surface: A Review of Transmission and Manifestations. Ocul Immunol Inflamm. 2020; 1-9. doi:10.1080/09273948. 2020.1772313.

3. Aiello, F., Gallo Afflitto, G., Mancino, R. et al. Coronavirus disease 2019 (SARS-CoV-2) and colonization of ocular tissues and secretions: a systematic review. Eye 2020; 34: 1206-1211. doi: doi.org/10.1038/s41433-020-0926-9

4. Seah I, Agrawal R. Can the Coronavirus Disease 2019 (COVID-19) Affect the Eyes? A Review of Coronaviruses and Ocular Implications in Humans and Animals. Ocul Immunol Inflamm. 2020; 28(3):391-395. doi: 10.1080/09273948.2020.17385 01.

5. Loffredo L, Pacella F, Pacella E, Tiscione G, Oliva A, Violi F. Conjunctivitis and COVID-19: A metaanalysis. J Med Virol. 2020;10.1002/jmv.25938. doi:10.1002/jmv. 25938

6. Olivares de- Emparan JP, Sardi-Correa C, LópezUlloa JA, Viteri-Soria J, Penniecook JA., JimenezRomán J, Lansingh V. COVID-19 and the eye: how much do we really know? A best evidence review. Arq Bras Oftalmol. 2020; 83(3):250-261.

7. Ulhaq ZS, Soraya GV. The prevalence of ophthalmic manifestations in COVID-19 and the diagnostic value of ocular tissue/fluid. Graefes Arch Clin Exp Ophthalmol. 2020; 8(6):1351-1352. doi: 10.1007/ s00417-020-04695-8.

8. Marinho PM, Marcos AAA, Romano AC, Nascimento H, Belfort R Jr. Retinal findings in patients with COVID-19. Lancet. 2020; 395(10237):1610. doi: 10.1016/S0140-6736(20)31014-X.

Recibido: $14 / 06 / 2020$

Aceptado: 08/07/2020 